\title{
Development of the Pain Appraisal Inventory: Psychometric properties
}

\author{
Anita M Unruh PhD MSW OT(C), Judith A Ritchie RN PhD
}

AM Unruh, JA Ritchie.

Development of the Pain Appraisal Inventory: Psychometric properties.

Pain Res Manage 1998;3(2):105-110.

OBJECTIVE: To discuss the development, content validity, internal consistency and factor structure of a Pain Appraisal Inventory (PAI).

DESIGN: A PAI was constructed with a threat appraisal scale and a challenge appraisal scale. Content validity was demonstrated with a panel of health experts. A sample of 309 individuals participated in a random community survey about troublesome pain in the two weeks preceding the telephone interview.

RESULTS: Confirmatory factor analysis produced a two-factor structure comprising threat appraisal and challenge appraisal. Cronbach's alphas were 0.86 for the threat scale and 0.81 for the challenge scale. Threat appraisal was correlated with respondents' scores on the McGill Pain Questionnaire, the Pain Disability Index, and measures of pain intensity and emotional upset due to pain. Challenge appraisal was reported by only $14 \%$ of the sample and limited the usefulness of statistical analyses for this variable. CONCLUSIONS: Appraisal of pain may be key to the underlying overall adjustment of an individual to pain. The PAI distinguishes between threat and challenge appraisal of pain, and may have considerable utility for the measurement of appraisal in experimental, epidemiological and clinical pain research.

Key Words: Appraisal, Community survey, Pain, Psychometric properties

\section{Développement du Pain Appraisal Inventory : propriétés psychométriques}

OBJECTIF : Discuter du développement, de la validité du contenu, de la cohérence interne et de la structure des facteurs du Pain Appraisal Inventory (PAI).

MODÈLE : Le PAI a été construit avec une échelle d'estimation de la menace et une échelle d'estimation du défi d'événements stressants. La validité du contenu a été démontrée par un groupe d'experts en santé. Un échantillon de 309 individus choisis au hasard dans la communauté a participé à une enquête sur la douleur incommodante au cours des deux semaines précédant l'entrevue téléphonique.

RÉSULTATS : Une analyse factorielle confirmatoire a produit une structure à deux facteurs comprenant l'estimation de la menace et l'estimation du défi. Les alphas de Cronback étaient 0,86 pour l'échelle concernant la menace et 0,81 pour l'échelle concernant le défi. L'appréciation de la menace a été corrélée avec les scores des répondants sur le McGill Pain Questionnaire, le Pain Disability Index et les mesures de l'intensité de la douleur et des troubles émotionnels causés par la douleur. L'estimation du défi a été rapportée seulement par $14 \%$ de l'échantillon limitant ainsi l'utilité des analyses statistiques pour cette variable.

CONCLUSIONS : L'appréciation de la douleur pourrait être la clé à l'adaptation globale sous-jacente d'un individu à la douleur. Le PAI établit une distinction entre l'estimation de la menace et l'estimation du défi de la douleur et pourrait être d'une utilité importante pour la mesure de l'estimation dans la recherche expérimentale, épidémiologique et clinique sur la douleur.

School of Occupational Therapy and School of Nursing, Dalhousie University, Halifax, Nova Scotia

Correspondence: Dr Anita M Unruh, School of Occupational Therapy, Dalhousie University, Halifax, Nova Scotia B3H 3J5. Telephone 902-494-8804, fax 902-494-1229, e-mail anita.unruh@dal.ca

Received for publication December 4, 1996. Accepted October 27, 1997 
A variety of measures have been developed to examine how people appraise their experiences of pain. Most of these measures are concerned with the individual's knowledge, attitudes or beliefs about pain and ability to manage pain (1-7). Another approach to the assessment of pain appraisal, based on the stress, appraisal and coping model proposed by Lazarus and Folkman, is to conceptualize pain as a stressor (8). This model was designed to distinguish between threat and challenge appraisals of stressful events, and identify relationships between appraisals and coping strategies. This model facilitates the comparison of appraisals of pain across diverse experiences of pain, including experimental pain, acute pain (eg, pain due to health procedures, sportsrelated injuries, unintentional injuries and others), recurrent pain, pain due to disease and chronic pain. Threat and challenge appraisals may be useful distinctions to examine appraisal of stressful events such as persistent pain. Threat appraisal refers to a negative interpretation of pain, whereas challenge appraisal reflects a more positive reconstruction of pain. Threat appraisals are likely to be associated with negative emotions such as anxiety and depression, and with activity restrictions (8-12). Threat appraisal may also be associated with health care utilization because previous studies have found that people do not seek health care for various health problems, including pain, if the problem is not perceived as serious enough $(12,13)$. Threat appraisal may have an important impact on the interference of pain with the roles and responsibilities of everyday life. Initial threat appraisal of stressors may need to be lowered, and sometimes shifted or redirected to reformulate the stressor as a challenge that can be managed and integrated into everyday life. Challenge appraisals may be linked with well-being and overall quality of life in the face of persistent health problems such as chronic pain, and may be an underlying component of hardiness or resilience.

Developing measures of threat and challenge appraisals reflects the tension between the need for macro-level global instruments that facilitate comparison of outcomes across stressors and descriptively richer, context-specific micromeasures $(8,14)$. In addition, varying definitions have been applied to 'threat' and 'challenge' in the development of these measures. Typically, definitions of threat and challenge have reflected specific concerns inherent in the nature of the stressor (9-12,14-16) or they have been embedded in a more generic measure of appraisal (Meaning of Illness Questionnaire) (17-19).

The purpose of the present study was to determine the reliability and validity of a measure of threat and challenge appraisal of pain that would be useful for a wide range of pain problems in a community sample and clinic samples. This study was part of a larger cross-sectional community survey concerned with relationships between the sex of the respondent, recent troublesome pain, characteristics of the pain, appraisal, coping strategies and health care utilization. Development of the Pain Appraisal Inventory (PAI), and its psychometric properties as exhibited in the community survey are discussed.

\section{MATERIALS AND METHODS}

\section{Sample}

Participants were selected using the SYSTAT Uniform Number Generator program (Systat Incorporated, Illinois) to identify a random number of households from the 1995 HalifaxDartmouth-Bedford telephone directory. One individual between the ages of 18 and 65 years who had pain in the previous two weeks was eligible to participate from each household. When there was more than one possible respondent in the household, the respondent whose pain was most recent to the time of the call was selected. All interviews were conducted in English.

Eighty-two per cent (1165) of 1430 households entered into the study were contacted. Ninety-seven people refused to participate before their eligibility could be determined - they objected to being solicited at home, believing the study to be a form of market research and/or doubting the random selection procedure. Of the 390 respondents who were considered eligible, 309 (79\%) agreed to participate (157 women, 152 men). Fifty-nine per cent of respondents were between the ages of 26 and 45 years, and $57 \%$ were married or living in a common-law relationship.

\section{Procedure}

Five experienced telephone interviewers (four women and one man) were trained in the interview procedures for this study. Telephone calls were made on weekdays between 18:00 and 21:00, on Saturdays from 11:00 to 18:00 and three days per week between 9:30 and 15:30. A maximum of five attempts were made to contact each household, varying calls by time and day of the week. Interviews were approximately 30 mins in length. The study was approved by the Faculty of Graduate Studies Ethics Committee at Dalhousie University, Halifax, Nova Scotia.

\section{Measures}

PAI: The PAI was developed in two initial studies concerned with the face validity, reliability and content validity of the inventory. Threat was defined as anticipated or actual physical or psychological harm, loss, injury or damage associated with a pain event. Challenge was defined as a test of strength, endurance or abilities, with the potential for growth, mastery or gain associated with a pain event.

In the first study, a threat scale and a challenge scale, each consisting of six statements, were constructed with six response options: strongly disagree, moderately disagree, slightly disagree, slightly agree, moderately agree and strongly agree. The result was a continuous scale with strong disagreement at one extreme and strong agreement at the other. Mean scores were generated for an overall threat or challenge score. A score greater than three indicated some degree of threat or challenge appraisal of pain. The inventory was administered to a convenience sample of undergraduate students, health professionals and community members $(n=46)$ with troublesome pain in the previous two weeks. On the basis of these responses, Cronbach's alpha was 0.78 for the 
TABLE 1

Percentage of respondents who agreed with individual appraisal statements

\begin{tabular}{|c|c|c|c|}
\hline Statement & Slightly agree (\%) & Moderately agree (\%) & Strongly agree $(\%)$ \\
\hline \multicolumn{4}{|l|}{ Threat appraisal } \\
\hline I am concerned that the pain might mean something is wrong with me & 20 & 21 & 22 \\
\hline I am concerned that the pain might become more than I can manage & 16 & 22 & 15 \\
\hline I am worried about getting things done & 19 & 25 & 16 \\
\hline I am concerned about how much more pain I can take & 22 & 16 & 8 \\
\hline The pain seems threatening & 18 & 13 & 7 \\
\hline I am worried about being depressed or discouraged because of the pain & 20 & 15 & 8 \\
\hline I feel controlled by the pain & 20 & 19 & 7 \\
\hline I think of this pain as a threat & 12 & 12 & 8 \\
\hline \multicolumn{4}{|l|}{ Challenge appraisal } \\
\hline I think the pain is a chance to prove myself & 7 & 4 & 2 \\
\hline I think the pain is a test of my strength and ability & 8 & 7 & 5 \\
\hline I think something good might come out of having the pain & 7 & 3 & 3 \\
\hline I think the pain makes me a stronger person & 11 & 7 & 3 \\
\hline I think the pain is a chance to learn more about myself & 14 & 8 & 3 \\
\hline I think that without this pain, there is no gain & 5 & 3 & 2 \\
\hline I think of this pain as a challenge & 13 & 6 & 4 \\
\hline I think the pain tests how well I can manage & 20 & 12 & 4 \\
\hline
\end{tabular}

threat scale and 0.67 for the challenge scale. The reliability analysis identified difficulty with two items.

Following further revision and the addition of four items, content validity of the PAI was determined in a second study by using an interdisciplinary panel of 18 health professionals with diverse research and clinical experience. Panel members were given the threat and challenge definitions, and asked to classify the 16 randomly ordered statements from the PAI according to whether the statement reflected a threat or challenge appraisal of pain. There was $100 \%$ correct classification for eight statements, $94 \%$ for six statements and $89 \%$ for one statement. One threat statement was classified correctly only $55 \%$ of the time. Further revisions of the wording improved the content validity. The final PAI was administered in the community telephone survey.

McGill Pain Questionnaire: The short form McGill Pain Questionnaire (MPQ) (20) was used to determine the concurrent criterion validity of threat and challenge appraisals. The MPQ is a well known pain evaluation tool with well documented reliability and validity (21-24). It is commonly used as a measure of sensory, affective and evaluative components of acute, chronic and experimentally induced pain.

Pain Disability Index: The Pain Disability Index (PDI) $(24,25)$ was used to determine the concurrent criterion validity of threat and challenge appraisals. The PDI is a brief measure of pain-related disability with seven items rated on an 11-point scale, with anchors of 'no disability' and 'total disability'. The reliability and validity of the PDI has been demonstrated in several studies (24-26). Because respondents in the present study were more likely to report tempo- rary, acute pain rather than ongoing chronic pain, 'disability' was changed to 'interference'. In addition, an item measuring disability in sexual activities was removed because it resulted in more negative responses during telephone interviews.

Intensity, duration and emotional upset due to pain: Intensity, duration and emotional upset were expected to be more strongly correlated with threat appraisals than with challenge appraisals of pain. Pain intensity is typically measured by single-item numerical or verbal rating scales, or a 10 $\mathrm{cm}$ visual analogue scale (27). These pain intensity scales have similar predictive and construct validities (27). However visual analogue measures of pain may be more subject to measurement error than numerical or verbal rating scales (28), and 11- and 21-point scales provide sufficient levels of discrimination (29). For these reasons, an 11-point scale for pain intensity $(0=$ not at all painful and $10=$ extremely painful) was used. For ease of administration, a similar 11-point scale was used for the measurement of emotional upset due to pain. Duration of pain was evaluated by using an 11-point scale $(0=$ one hour or less and $10=10$ days or more).

Pain location: Respondents were asked to describe the nature of their pain. This information was then used to identify five locations of pain: head; musculoskeletal; abdomen or side; chest or breast; and pelvis, groin, genital or rectum.

\section{RESULTS}

Troublesome pain was very common in this sample. Household prevalence of troublesome pain in the previous two weeks was $46 \%$. Fifty-three per cent of 309 respondents had pain at the time of the interview. Sixty-eight per cent of re- 
TABLE 2

Factor analysis of the Pain Appraisal Inventory

\begin{tabular}{|c|c|c|c|c|}
\hline Statement & Factor 1 & Factor 2 & Factor 1 & Factor 2 \\
\hline \multicolumn{5}{|l|}{ Threat statements } \\
\hline I am concerned that the pain might mean something is wrong with me & 0.63 & 0.03 & 0.64 & 0.14 \\
\hline I am concerned that the pain might become more than I can manage & 0.79 & -0.003 & 0.79 & 0.13 \\
\hline I am worried about getting things done & 0.68 & -0.04 & 0.68 & 0.06 \\
\hline The pain seems threatening & 0.76 & 0.05 & 0.77 & 0.18 \\
\hline I am worried about being depressed or discouraged because of the pain & 0.70 & 0.10 & 0.71 & 0.22 \\
\hline I feel controlled by the pain & 0.67 & -0.07 & 0.66 & 0.03 \\
\hline I think of this pain as a threat & 0.72 & 0.02 & 0.72 & 0.14 \\
\hline \multicolumn{5}{|l|}{ Challenge statements } \\
\hline I think the pain makes me a stronger person & -0.12 & 0.73 & 0.01 & 0.71 \\
\hline I think the pain is a chance to learn more about myself & 0.13 & 0.62 & 0.24 & 0.64 \\
\hline I think that without this pain, there is no gain & 0.03 & 0.51 & 0.12 & 0.51 \\
\hline I think of this pain as a challenge & -0.02 & 0.70 & 0.09 & 0.70 \\
\hline I think the pain tests how well I can manage & 0.18 & 0.69 & 0.29 & 0.72 \\
\hline
\end{tabular}

spondents reported persistent or ongoing pain in the previous year. The majority of reported pains were musculoskeletal $(n=182)$ or head pain $(n=80)$.

\section{Duration, intensity and emotional upset}

Many of the respondents (68\%) experienced persistent or ongoing pain in the previous year. For most respondents, pain persisted over several days during the reporting period -36 $(12 \%)$ had pain for one day or less, whereas $131(42 \%)$ experienced pain for 10 days or more over the two weeks. The majority of respondents (65\%) had experienced this pain more than 20 times in their life. Although many of these pains may have been acute, other pains may have been recurrent or persistent in nature. The mean intensity of the reported pains was $6.0(\mathrm{SD}=1.9)$. Intensity of pain was correlated with the MPQ affective score $(\mathrm{r}=0.50, \mathrm{P}<0)$ and the MPQ sensory score $(\mathrm{r}=0.57, \mathrm{P}<0)$. Mean emotional upset due to pain was $4.06(\mathrm{SD}=3.0)$. Emotional upset was correlated with the MPQ affective score $(\mathrm{r}=0.48, \mathrm{P}<0)$ and the MPQ sensory score $(r=0.40, \mathrm{P}<0)$.

\section{Mean threat and challenge scores, and endorsement of individual items}

Mean threat appraisal in this sample was 3.1 ( $\mathrm{SD}=1.3$, range one to six). Fifty-one per cent had a threat appraisal greater than three, and $31 \%$ had a threat appraisal greater than four. The percentage of respondents who agreed with individual threat statements ranged from $32 \%$ to $63 \%$ (Table 1). Mean challenge appraisal was $1.9(\mathrm{SD}=0.94)$. The majority of re- spondents did not appraise their pain as a challenge, resulting in a skewed distribution of the data for this variable. The percentage of respondents who agreed with individual challenge statements ranged from $10 \%$ to $32 \%$. The low endorsement of items suggested that the majority of people who had experienced a recent troublesome pain in a general population did not appraise this pain as a challenge. For this reason, descriptive comparisons rather than statistical analyses were used to examine the relationship between challenge appraisal and other measures.

\section{Internal consistency of the PAI}

Cronbach's alphas for the PAI in this sample were 0.86 for the threat scale and 0.81 for the challenge scale. A confirmatory factor analysis, using principal axis with oblique rotation and two factors requested, identified two factors. The factor structure matrix of partial regression coefficients for each item with both factors, clearly divided threat and challenge items into two separate scales (Table 2). Similarly, individual scale items had strong correlations with only one factor (Table 2). The factors themselves had low correlations with each other, as expected $(r=0.16)$.

\section{Concurrent criterion validity of the PAI}

There have been no published reports of the use of the short form MPQ (24) in a general population. As may be expected, the internal consistency of the MPQ was moderate in this sample, with Cronbach's alphas for the sensory and affective scales 0.69 and 0.61 , respectively. Although the PDI $(25,26)$ 
was modified for use in this survey, the internal consistency of this measure remained high, with a Cronbach's alpha of 0.87 . Threat appraisal was moderately correlated with the MPQ sensory $(\mathrm{r}=0.40, \mathrm{P}<0.001)$ and affective scales $(\mathrm{r}=0.55$, $\mathrm{P}<0.001)$, the PDI ( $\mathrm{r}=0.55, \mathrm{P}<0.001)$, and ratings of pain intensity $(\mathrm{r}=0.39, \mathrm{P}<0.001)$ and emotional upset due to pain $(\mathrm{r}=0.56, \mathrm{P}<0.001)$. Threat appraisal increased to some degree with increasing duration of pain $(\mathrm{r}=0.15, \mathrm{P}<0.01)$.

There was no significant age or sex difference in threat appraisals of pain. Pain located in the head had the lowest threat appraisal (2.9), whereas pains located in the chest, breast, pelvis, groin, genitals or rectum were appraised as more threatening (3.8).

\section{Characteristics of challenge appraisals of pain}

Although 158 respondents (51\%) reported threat appraisal of pain greater than three, only 43 individuals $(14 \%, 21$ women, 22 men) reported challenge appraisals greater than three. The differences between these two groups are not clear. Ratings of pain intensity, emotional upset, the MPQ sensory and affective scores, and the PDI score in these two groups were very similar. Seventy per cent of individuals who had challenge scores greater than three reported musculoskeletal pain. The highest challenge appraisals were reported by respondents who had pain due to a health procedure, suggesting that when pain is anticipated, associated with a potentially positive health outcome and adequately treated, pain itself may be perceived as less threatening.

Although respondents with threat or challenge appraisals of pain did not appear to differ greatly on aspects of the pain experience, there were some socioeconomic differences. Respondents who reported challenge appraisals were more likely to have pain at the time of the interview than those who reported threat appraisals (72\% versus 58\%). They were more often single, separated or divorced, or widowed ( $51 \%$ versus $46 \%$ ), and less likely to have children at home (58\% versus $49 \%$ ). Respondents who reported challenge appraisals were more likely to be less than 36 years of age ( $51 \%$ versus $44 \%$ ), to have part-time employment or student responsibilities, or to have worked within the home ( $51 \%$ versus $42 \%$ ). Men and women were equally likely to report threat or challenge appraisals of their pain. Higher challenge appraisals did not preclude a moderate or high threat appraisal. Twenty-two respondents (11 women, 11 men) reported challenge and threat appraisals greater than three.

\section{DISCUSSION}

The distinction between threat and challenge appraisals may have important implications for health care for pain. Threat appraisals may carry an increased likelihood of anxiety and depression, whereas challenge appraisals may be central to adequate management of chronic health problems, such as pain $(30,31)$. Further, altering a threat appraisal of pain to a challenge appraisal may improve psychological adjustment to chronic pain and reduce the associated interference with occupations and responsibilities of daily life.

Both threat and challenge scales of the PAI had excellent internal reliability and content validity. The test-retest reliability of the PAI is not known. Threat appraisal was significantly correlated with intensity and duration of pain, suggesting that appraisal of pain may be partially influenced by the severity and persistence of pain. In contrast to traits such as intelligence, pain is a less stable phenomenon because pain can show considerable change and fluctuation over time. Appraisal of pain is likely to respond to changes in characteristics of the pain and to social factors inherent in any specific pain event, particularly for acute pains. However, it is possible that as acute pain persists and becomes chronic, appraisal of pain becomes more stable. Further, it is also possible that an individual's appraisal of persistent pain or highly familiar pain is relatively stable over time.

As expected, threat appraisal correlated with sensory and affective scales of the MPQ (23), the PDI $(24,25)$, and measures of pain intensity and emotional upset due to pain, demonstrating the concurrent validity of the threat scale in the PAI. Challenge appraisal of pain was reported infrequently. Challenge appraisals may be more prominent in individuals with persistent or chronic pain, and may also be specific to certain types of pain such as sports-related pain, labour or pain due to health procedures. Respondents with challenge appraisals of their pain were younger and appeared to have fewer responsibilities, such as those that might be associated with full-time employment, marital or common-law relationships, and raising children.

The relationship of appraisal to coping and quality of life has not been determined. Threat and challenge appraisals of pain are likely to be influenced by characteristics of the pain, the context in which the pain occurs and personal qualities of the individual with pain. Further research is needed to determine how appraisals of acute and chronic pain differ, whether challenge appraisals are important in maintaining quality of life, and whether threat appraisals can be modified where appropriate.

ACKNOWLEDGEMENTS: This study was supported by a Medical Research Council of Canada doctoral studentship and a Canadian Occupational Therapy Foundation graduate scholarship to Dr Anita Unruh. The authors thank Dr Harold Merskey for his helpful comments.

\section{REFERENCES}

1. Jensen MP, Karoly P, Huger R. The development and preliminary validation of an instrument to assess patients' attitudes toward pain. J Psychosom Res 1987;31:393-400.

2. Jensen MP, Karoly P. Pain-specific beliefs, perceived symptom severity, and adjustment to chronic pain. Clin J Pain 1992;8:123-30.

3. Flor H, Behle DJ, Birbaumer N. Assessment of pain-related cognitions in chronic pain patients. Behav Res Ther 1993;31:63-73.

4. Anderson KO, Dowds BN, Pelletz RE, Edwards WT, PeetersAsdourian C. Development and initial validation of a scale to measure self-efficacy beliefs in patients with chronic pain. Pain 1995;63:77-84.

5. Slater MA, Hall HF, Atkinson JH, Garfin SR. Pain and impairment beliefs in chronic low back pain: Validation of the Pain and Impairment Relationship Scale (PAIRS). Pain 1991;44:51-6.

6. Smith CA, Wallston KA. Adaptation in patients with chronic 
rheumatoid arthritis: application of a general model. Health Psychol 1992;11:151-62.

7. Riley JF, Ahern DK, Follick MJ. Chronic pain and functional impairment: Assessing beliefs about their relationship. Arch Phys Med Rehabil 1988;69:579-82.

8. Lazarus RS, Folkman S. Stress, Appraisal and Coping. New York: Springer Publishing Company, 1984

9. Folkman S, Lazarus RS, Dunkel-Schetter C, DeLongis A, Gruen RJ. The dynamics of a stressful encounter: cognitive appraisal, coping, and encounter outcomes. J Pers Soc Psychol 1986;50:992-1003.

10. Arathuzik D. The appraisal of pain and coping in cancer patients. West J Nurs Res 1991;13:714-31.

11. Arathuzik D. Pain experience for metastatic breast cancer patients. Unraveling the mystery. Cancer Nurs 1991;14:41-8.

12. Klonoff EA, Landrine H, Brown MA. Appraisal and response to pain may be a function of its bodily location. J Psychosom Res 1993;37:661-70

13. Jones RA, Wiese HJ, Moore RW, Haley JV. On the perceived meaning of symptoms. Med Care 1981;19:710-7.

14. Dewe P. Primary appraisal, secondary appraisal and coping: their role in stressful work encounters. J Occup Psychol 1991;64:331-51.

15. Arathuzik D. Preliminary assessment: the Pain Inventory and the Pain Coping Tool. Am J Hosp Palliat Care 1994;11:25-9.

16. Mendola R, Tennen H, Affleck G, McCann L, Fizgerald T. Appraisal and adaptation among women with impaired infertility. Cognit Ther Res 1990;14:79-93.

17. Browne G, Byrne C, Roberts J, et al. The Meaning of Illness Questionnaire: reliability and validity. Nurs Res 1988;37:368-73.

18. McAdams C, Byrne C, Browne G. Meaning of Illness Questionnaire. Questionnaire and scoring manual. Hamilton: School of Nursing, McMaster University, 1989.

19. Weir R, Browne G, Roberts J, Tunks E, Gafni A. The Meaning of
Illness Questionnaire: further evidence for its reliability and validity. Pain 1994;58:377-86.

20. Melzack R. The short-form McGill Pain Questionnaire. Pain 1987;30:191-7

21. Melzack R, Katz J. Pain measurement in persons in pain. In: Wall PD, Melzack R, eds. Textbook of Pain, 3rd edn. New York: Churchill Livingstone, 1994:337-51.

22. Love A, Leboeuf DC, Crisp TC. Chiropractic chronic low back pain sufferers and self-report assessment methods. Part 1. A reliability study of the Visual Analogue Scale, the pain drawing and McGill Pain Questionnaire. J Manipulative Physiol Ther 1989;12:21-5.

23. Dubuisson D, Melzack R. Classification of clinical pain descriptions by multiple group discriminant analysis. Exper Neurol 1976;51:480-7.

24. Pollard CA. Preliminary validity study of the Pain Disability Index. Percept Mot Skills 1984;59:974.

25. Tait RC, Pollard CA, Margolis RB, Duckro PN, Krause SJ. The Pain Disability Index: psychometric and validity data. Arch Phys Med Rehabil 1987;86:438-41.

26. Tait RC, Chibnall JT, Krause S. The Pain Disability Index: psychometric properties. Pain 1990;40:171-82.

27. Jensen MP, Karoly P, Braver S. The measurement of clinical pain intensity: A comparison of six methods. Pain 1986;27:117-26.

28. McDowell I, Newell C. Measuring Health: A Guide to Rating Scales and Questionnaires. Oxford: Oxford University Press, 1987.

29. Jensen MP, Turner JA, Romano JM. What is the maximum number of levels needed in pain intensity measurement? Pain 1994;58:387-92.

30. Barkwell DP. Ascribed meaning: A critical factor in coping and pain attenuation in patients with cancer-related pain. J Palliat Care 1991;7:5-14.

31. Croyle RT. Appraisal of health threats: cognition, motivation, and social comparison. Cognit Ther Res 1992;16:165-82. 


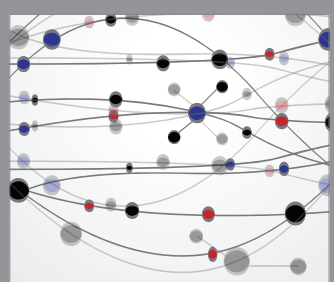

The Scientific World Journal


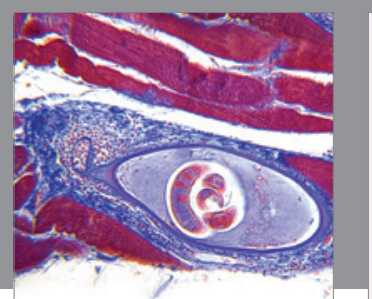

Gastroenterology Research and Practice

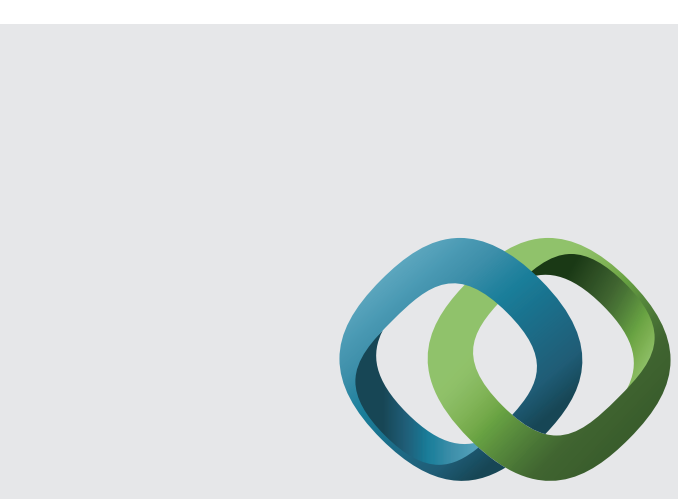

\section{Hindawi}

Submit your manuscripts at

http://www.hindawi.com
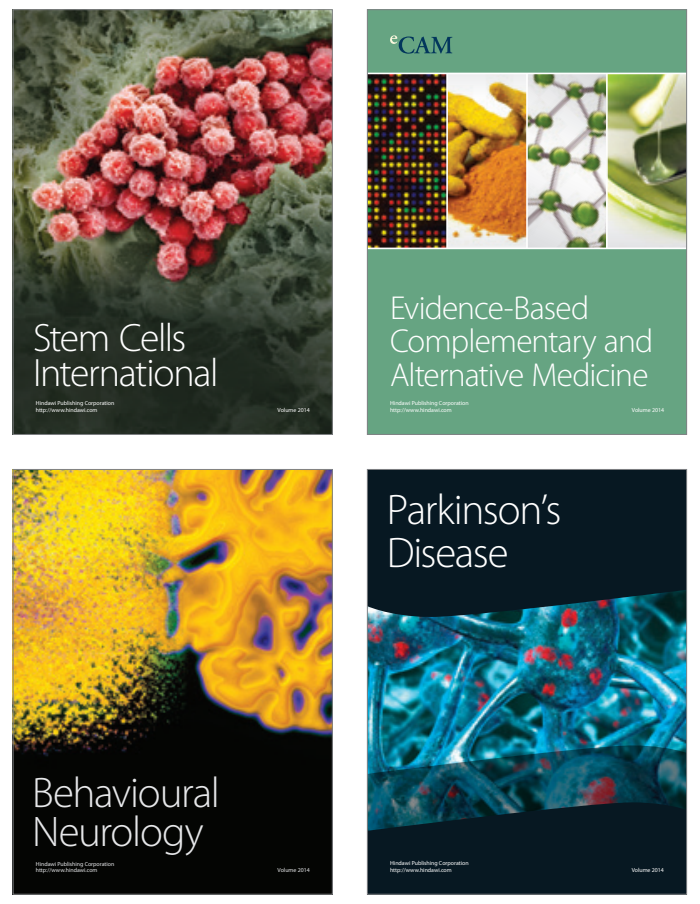
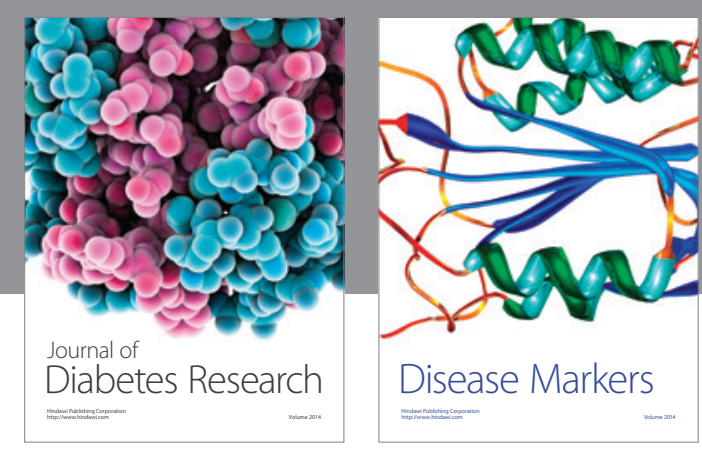

Disease Markers
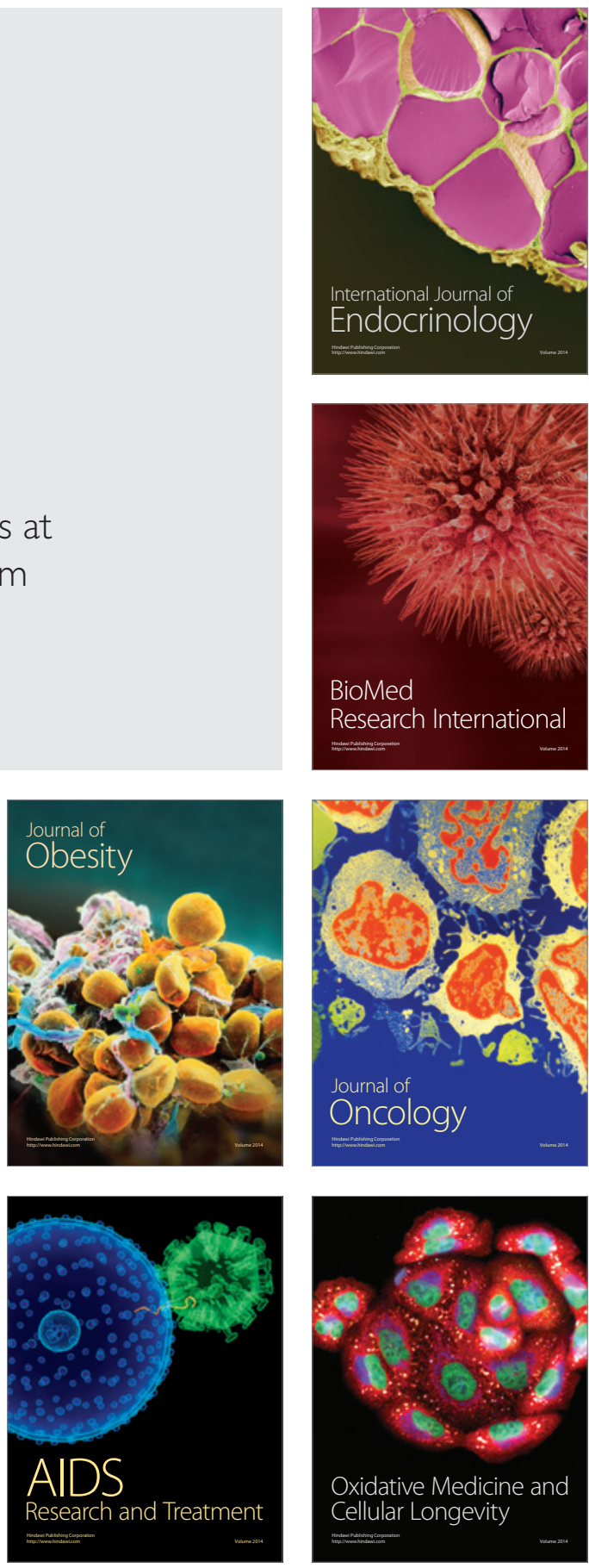